\title{
Belgesel Çekme Etkinliğinin Fen Bilgisi Öğretmen Adaylarının Sürdürülebilir Kalkınma için Çevreye Yönelik Tutumları Üzerindeki Etkisi
}

\section{Hülya ASLAN EFE*, Sait YÜCEL**, Rıfat EFE***}

Öz: Bu araştırmada, belgesel çekme etkinliğinin öğretmen adaylarının çevreye yönelik tutumları üzerindeki etkisi araştırılmıştır. Araştırmada kontrol gruplu ön test son test yarı deneysel desen kullanılmıştır. Araştırmada deney grubunda yer alan öğretmen adayları belirlenen dört ayrı temaya yönelik belgesel hazırlamışlardır. Araştırmaya, Diyarbakır'da bir devlet üniversitesinde öğrenim gören 61 fen bilgisi öğretmen adayı katılmıştır. 2017-2018 eğitim öğretim yılı bahar dönemi boyunca gerçekleşen deneysel süreç sonunda deney grubunda öğrenim gören öğretmen adaylarının çevreye yönelik ekosentrik tutumlarının olumlu yönde geliştiği belirlenmiştir. Çevre eğitimi derslerinde sınıf dışı öğrenme etkinliklerinin arttırılması araştırmanın önerileri arasındadır.

Anahtar kelimeler: Çevre, Tutum, Belgesel, Fen Bilgisi Öğretmen Adayları

\section{The Effect of Making Documentaries on Science Student Teachers' Attitudes towards the Environment for Sustainable Development}

Abstract: In this study, the effect of making documentaries on science student teachers' attitudes towards the environment for sustainable development was investigated. A quasi-experimental design involving pre-, post- test control group was used. Participant student teachers in the experimental group prepared documentaries for four different identified themes. Sixty-one (61) science student teachers studied at a state university in Diyarbakır participated in the research. The study revealed that, in the experimental group, the participant science student teachers' ecocentric attitudes developed positively at the end of the experimental process during the spring semester of

\footnotetext{
* Sorumlu yazar, Doç.Dr., Dicle Üniversitesi, Z.G.Eğitim Fakültesi, Fen Bilgisi Öğretmenliği ABD, hulyaefe@dicle.edu.tr, https://orcid.org/0000-0002-0042-4546

** Prof.Dr., Dicle Üniversitesi, Z.G.Eğitim Fakültesi, Fen Bilgisi Öğretmenliği ABD, syucel@dicle.edu.tr, https://orcid.org/00000002-9626-7708

*** Prof.Dr., Dicle Üniversitesi, Z.G.Eğitim Fakültesi, Biyoloji Öğretmenliği ABD, rifatefe@dicle.edu.tr, https://orcid.org/00000002-8196-309X
} 
2017-2018 academic year. Increasing out-of-classroom learning activities in environmental education courses are among the suggestions of the research.

Keywords: Environment, Attitude, Documentary, Science Student Teachers

\section{Giriş}

İnsanoğlu yaşadığı ekosistemden etkilenmekle beraber çeşitli faaliyetleri sonucu ekosistemi etkilemektedir. Hızlı büyüyen nüfus ve ekonomik gelişme, kentleşmenin ve sanayileşmenin kontrolsüz büyümesi ve ormanların tahrip olması nedeniyle bir dizi çevresel sorun ortaya çıkmaktadır. Orman ve toprağın tarımsal bozulması, su, maden, kum, kaya gibi kaynakların tükenmesi, biyolojik çeşitlilik kaybı en göze çarpan sorunlar arasındadır (Anand, 2013). Çevresel problemlerin neden olduğu bozulmanın en önemli özelliği tüm insanlığı etkilemesidir (Khan, 2013). Çevresel problemlerin insanların yaşam koşullarını olumsuz yönde etkilemeye başlaması, ekonomik gelişmelerin doğal kaynakların yetmezliği sebebiyle çıkmaza gireceğinin ön görülmesi sürdürülebilir kalkınmanın önemini artırmıştır (Ergülen ve Büyükkeklik, 2008). Çevresel kaynakların tasarruflu kullanımını amaçlayan sürdürülebilir kalkınma; çevresel denge ve ekonomik gelişmeyi birlikte ele alan çevresel kaliteye önem veren bir kavramdır (Gürlük, 2001). Doğal kaynakların yeni neslin ihtiyaçlarını da karşılayacak şekilde kullanımı (Tietenberg, 2006) olarak tanımlanan sürdürülebilir kalkınma, dünya gündeminde tartışılan konuların başında gelmektedir. Sürdürülebilir kalkınma sosyal, çevresel ve ekonomik olmak üzere üç boyutta ele alınmaktadır (Birleşmiş Milletler, 2002). Son zamanlarda sürdürülebilir kalkınmanın çevresel boyutuyla ilgili ekosentrik ve antroposentrik yaklaşımlar ön plandadır. Her iki yaklaşımda sürdürülebilir kalkınmanın analizinde canlı organizmaların doğal ortamında korunmasına önem verse de dayandıkları teori birbirinden farklıdır (Thompson ve Barton, 1994). Ekosentrik “doğa merkezli” yaklaşımın temelinde doğaya değer vermek vardır. Bu yaklaşıma göre doğa, hayvanları ve bitkileriyle birlikte, ekonomik nedenlerden bağımsız olarak koruma önlemlerinin alınmasıyla korunmalıdır. İnsan da doğanın ve doğal yaşamın bir parçasıdır. Doğa ve tabiat varlıklarının özündeki bu değerden dolayı ekosentrik yaklaşımın savunucuları, doğaya hayranlık ve sayg1 duyarak önem vermek gerektiğini savunmaktadırlar (MacKinnon ve Fiala, 2014). Ekosentrik yaklaşım, doğanın sadece insanların sürdürmesi için bir kaynak olmadığını, insandan bağımsız olduğunu, tamamen kendi başına var olduğunu ve varoluşundan beri kendine özgü bir değeri 
olduğunu savunmaktadır (Oelschlager, 1992). Bu yaklaşımın savunucuları, sanayileşmenin ve sanayinin şekillendirdiği modern yaşam tarzının insanın doğadan ve doğal yaşamdan farklı olduğu algısını tetiklediğini öne sürmektedir. $\mathrm{Bu}$ nedenle insanların, doğaya ve doğal yaşama yabancılaşarak doğal yaşamdan korkmaya başladıkları savunulmaktadır (Louv, 2008; Schultz, 2000). Örneğin, ekosentrik kişiler yağmur ormanlarının kesilmemesi gerektiğini, çünkü aksi takdirde orada yaşayan bitki ve hayvan türlerinin yok olabileceği düşüncesine sahiptirler (Kortenkamp ve Moore, 2001).

Antroposentrik yaklaşım ise doğaya, maddi, fiziksel ve diğer somut faydaları nedeniyle değer verir. Antroposentrizim, doğanın kendi başına değerli olduğu fikrini dışlayan materyalist bir görüş olarak karşımıza çıkmaktadır. Bununla birlikte, antroposentrik yaklaşıma göre, insanların çevre dostu eylemleri insanlara faydası var ise teşvik edebilir. Örneğin, Doğa harikaları insan refahını arttırırsa, doğa korumaya değer olabilir (Karpiak ve Baril, 2008; Nordlund ve Garvill, 2002). Ayrıca bu yaklaşım çevre veya doğanın kendi başına bir değeri olmadığını savunmakta ve çevrenin değerini insanı nasıl etkilediğine (MacKinnon ve Fiala, 2014) ve insanlara sağlayabileceği imkânlara göre değerlendirmektedir (Thompson ve Barton, 1994). Antroposentrik kişiler, insanların yaşamının devamı, bu sürecin niteliği için çevrenin korunması gerektiğine inanırlar ve insanlığa yararını göz önünde bulundururlar. Bu kişilerde çevresel sorunlar, insan sağlığına yönelik bir tehdit oluşturabileceği için önlenmeli; enerji ihtiyacımızın karşılanmasında doğal kaynakların önemli yeri olduğu için tutumlu kullanılmalı düşüncesi hâkimdir. Bu durumda antroposentrik tutumlar faydacı felsefeye dayanmaktadır (Erten, 2007). Açıklanan antroposentrik ve ekosentrik yaklaşımların yanında antipatik tutumlar da bulunmaktadır. $\mathrm{Bu}$ tutumların, artan çevre koruma hareketlerine karşı bir tepki olarak ortaya çıktığı düşünülmektedir (Atlı, Uzun, Saraç, Sağlam ve Sağlam, 2015).

\section{Neden Belgesel Çekme Etkinliği}

Toplumsal ve yapısal değişime ilham verecek çevre eğitimi inşa etmek, yaratıcı eğitim, becerikli işbirliği ve sivil katılım gerektirmektedir. Türkiye'de çevre eğitiminin gelişimi için, geniş bir yelpazede insanları bir araya getiren, sorunların uygun şekilde yorumlanmasını kolaylaştıran ve yenilikçi, ileriye dönük çözümler sunan stratejilere ihtiyaç duyulmaktadır. Bu stratejilerden biri çevresel belgeselleri hazırlama ve kullanmadır. Çevresel belgesel, çevresel sorunların gerçekliğini dramatik hale getirme ve izleyicileri çevresel krizleri ele almak için gerekli olan değişimin aktif 
bir parçası haline getirme yeteneğine sahiptir. Çevresel belgeseller, doğal ortamla ilgili bir dizi resim, ses, kaynak ve bilginin pedagojik söylem haline dönüştürüldüğü ana ortamı oluşturur (Paschalidis 2006). Çevresel belgeseller çağdaş görsel-işitsel araçların sunduğu teknolojik firsatlarla birleştirilirse, değerli bir eğitim materyali haline dönüşmektedir. Zengin içeriğiyle çevresel belgeseller, bütün eğitim kademelerinde öğretim materyali olarak çoklu kullanım alanı sunmaktadır. Özel öğretim ihtiyaçlarına kolayca adapte edilebilir ve öğrencilerin çevre bilincinin gelişimini sağlayan bir araç olarak hizmet edebilir (Palmer ve Lee, 2009). Çevresel belgeseller, çevre sorunları hakkında hikayeler anlatmanın da bir yoludur. Bu hikayeler profesyonel aktörlerden ziyade gerçek insanları içeren ve gerçek çevre sorunlarını temsil eden bir içeriğe sahip olmakla beraber izleyicilerde daha derin bir empati oluşturma gücüne sahiptirler (Godmilow ve Shapiro, 1997). Görsel, işitsel ve anlatı deneyimleriyle belgeseller, çevre konularında geniş bir yelpazedeki insanlara ulaşma ve bunları etkileme konusunda büyük bir potansiyel göstermektedir (Bahk, 2010). Belgesel hazırlama ile doğaya ilgiyi, empatiyi arttıran ve daha bilinçli bireyler oluşturan bir öğrenme sürecini gerçekleştirilir (Palmer ve Lee, 2009). Bu bağlamda bu araştırma kapsamında öğretmen adayları dönem boyunca çevresel belgeseller hazırlamışlardır. Çevre eğitimi belgesellerinin hazırlanması öğretmen adaylarına, teknolojinin tüm olanaklarından faydalanma firsatı sunmuştur. Öğretmen adaylarının belgesel hazırlamaları uygulamalı teknoloji kullanımına olanak sağlamakla birlikte, sınıfta teknolojinin kullanımına da mükemmel bir örnek oluşturmaktadır. Çevresel belgesellerin hazırlanması, öğretmen adaylarının akademik konu ile ilgili deneyimi yaşama şansı yaratmıştır.

Ayrıca, çevresel belgeseller ile öğretmen adayları ne yaptıklarını, hissettiklerini, doğayı algılama biçimlerini ve öğrendiklerini yansıtmak için fırsatlar yakalamışlardır. Böylece sınıf ile doğa arasında öğrenim köprüsü oluşturulması için kendi yollarını kullanmışlardır. Oluşturdukları bu köprünün çevreye yönelik tutumlarını nasıl etkileyeceği araştırma sorularına yön vermiştir.

\section{Neden Tutum Geliştirme}

Tutumlar, insanların çevrelerindeki nesnelerin genel değerlendirmeleri olarak sosyal bilimlerde çokça araştırılan konulardan biri haline gelmiştir. Sosyoloji, siyaset bilimi, ekonomi, antropoloji ve eğitim alanları, insanın beğenisine ve hoşlanmadı̆̆ı şeylere ilgi gösteren birçok disiplinden sadece birkaçıdır. Nitekim tutumlar birçok araştırmada sosyal psikoloji alanındaki "en 
belirgin ve vazgeçilmez kavram" olarak adlandırılmıştır (Allport, 1935). Tutumların pratik ve teorik olarak önemli olmasının nedenlerinden biri, davranış üzerinde öngörülebilir ve çok güçlü etkilerinin olmasıdır (Greenwald, 1989). Bununla birlikte, hangi tutumların hangi koşullar altında hangi davranışların en doğru şekilde tahmin edildiğinin belirlenmesi yarım yüzyıldan fazla bir süredir araştırmaları teşvik eden oldukça karmaşık bir girişim haline gelmiştir. Tutum, bireysel bir düşünme ve fenomen üzerinde hareket etme şeklidir. Olumlu tutum, bireylerin girişim alanında mükemmelliğe ulaşmalarını sağlar. Tersine, olumsuz tutum birinin verilen görevde kendini depresyonda hissetmesine ve ilerlememesine neden olur (Judi, Sahari, Ashaari ve Wook, 2010). Bu nedenle tutum, eğitimciler için en önemli elementlerden biri olarak gösterilmektedir. Dunlap ve Van Liere (1978) çalışmalarında, dünyada yaşanan ekolojik krizin kaynağını bireylerin sahip olduğu çevresel inanç, tutum ve değerlerin neden olduğuna işaret etmektedirler. Bu nedenle, bireylerin çevre sorunlarını çözmek için çevreye karşı tutumlarını derhal değiştirmesi gerektiği kabul edilmektedir. İnsanların olumlu tutum geliştirmesi durumunda değişimin ortaya çıkacağı birçok araştırmacı tarafından vurgulanmaktadır (Anderson ve ark., 2007; Greenwald, 1989; Poortinga, Steg ve Vlek, 2004; Rowe, 2002). Bu nedenle araştırmada öğretmen adaylarının çevreye yönelik tutumlarını değiştirmeye yönelik çalışmalar yapıllmıştır.

\section{Araştırmanın Amacı}

Doğayı anlayan, seven ve koruyan bireylerin yetişmesi ancak doğa ile etkileşimde bulunabilecekleri eğitimsel süreçlerden geçmeleri ile mümkün olacaktır (Ewert, Place ve Sibthorp, 2005; Taff, Aziz, Haron, Rashid ve Yasim, 2010). Bu noktada doğa ile etkileşimli fen öğretmenlerinin değeri ortaya çıkmaktadır. Bu bağlamda, geleceğin öğretmenlerinin lisans düzeyinde öğrenim gördükleri zaman diliminde çevreye yönelik ekosentik tutumlarının geliştirilmesi önem arz etmektedir. Çünkü çevre eğitiminin başarılı olarak gerçekleşmesinde öğretmenler önemli rol oynamaktadır (Selvi, 2007). Bu nedenle öğretmen adaylarının sahip oldukları çevresel tutumların pozitif yönde geliştirilmesi gerekmektedir. Literatür incelendiğinde, farklı öğretim kademesindeki öğrencilerin (Atlı, Uzun, Saraç,, Sağlam, ve Sağlam, 2015; Kopnina ve Cocis, 2017a), üniversite öğrencilerinin (Casey ve Scott, 2006; Crumpei, Boncu ve Crumpei, 2014; Kortenkamp ve Moore, 2001; Kopnina, 2013; Kopnina ve Cocis, 2017b), öğretmen adaylarının (Alpak Tunç ve Yenice, 2017; Erten ve Aydoğdu, 2011; Karakaya ve Çobanoğlu, 
2012; Sürmeli ve Saka, 2013) ve farklı meslek gruplarına dahil bireylerin (Akgül, Birinci, Göral ve Karaküçük, 2007; Baltacı, Yirik, Sargın ve Yumuşak, 2015) örneklem olarak seçildiği araştırmalar dikkatleri çekmektedir. Bu araştırmaların tamamının çevresel tutum yaklaşımlarının genel durumunu ortaya koymak için tarama yöntemiyle gerçekleştiği görülmektedir. Öğretmen adaylarının çevresel tutum yaklaşımlarını değiştirmeye yönelik deneysel çalışmaya rastlanmamıştır. Bu yönüyle araştırmanın önemi ortaya çıkmaktadır. Bu araştırmada, fen bilimleri öğretmen adaylarının çevreye yönelik tutum yaklaşımlarının belgesel çekme etkinliği ile geliştirmek amaçlanmaktadır. Bu bağlamda aşağıdaki araştırma sorularına yanıt aranmıştır.

1. Kontrol grubu öğretmen adaylarının ön test son test ekosentirik, antroposentrik ve antipatik tutumlarının karşılaştırmaları arasında anlamlı bir farklılık var mıdır?

2. Deney grubu öğretmen adaylarının ön test son test ekosentirik, antroposentrik ve antipatik tutumlarının karşılaştırmaları arasında anlamlı bir farklılık var mıdır?

3. Kontrol ve deney grubu öğretmen adaylarının son test ekosentirik, antroposentrik ve antipatik tutumlarının karşılaştırmaları arasında anlamlı bir farklılık var mıdır?

\section{Yöntem}

Bu çalışmada, nicel araştırma yöntemlerinden ön test son test kontrol gruplu deneysel desen kullanılmıştır.

\section{Katılımcilar}

Araştırmaya 2017-2018 Eğitim-Öğretim yılı Bahar döneminde Diyarbakır'da bir devlet üniversitesinde öğrenim görmekte olan 61 (Kontrol:29; Deney:32) öğretmen adayı katılmıştır.

\section{Deneysel Süreç}

Araştırma kapsamında kontrol grubunda çevre eğitimi dersi mevcut programın öngördüğü yöntem ile işlenmiştir. Kontrol grubu öğretmen adayları ile Yüksek Öğretim Kurulu tarafından hazırlanan çevre eğitimi dersi öğrenme çıktıları dikkate alınarak hazırlanan slaytlar ile konular işlenmiştir. "Biyolojik Çeşitlilik ve Türkiye'deki Durumu” ünitesi sınıf dışı etkinliklerle desteklenmiştir. $\mathrm{Bu}$ bağlamda üniversitenin kampüsündeki biyoçeşitlilik incelenmiştir. Ayrıca "Çevre ile İlgili yeni yaklaşımlar” ünitesi kapsamında araştırmacılar ile öğretmen adayları "Diyarbakır Çevsan Geri Dönüşüm Tesisine” ziyarette bulunmuşlardır.

Araştırma kapsamında deney grubu öğretmen adayları ile çevre eğitimi dersi kontrol grubunda olduğu gibi işlenmiştir. Kontrol grubu ile gerçekleştirilen sınıf dışı öğrenme etkinlikleri deney 
grubu ile benzer şekilde uygulanmıştır. Bunlara ek olarak deney grubundaki öğretmen adayları belirlenen çevre eğitimi temalarına yönelik belgesel çekmişlerdir. Deney grubunda öğrenim gören 32 öğretmen adayı 4 kişiden oluşan heterojen gruplara ayrılmıştır. Bu sekiz gruptan "Ekolojide türler arası ve tür içi ilişkiler”. "Besin zinciri”. "Madde döngüleri” ve "Çevre sorunları" konularına uygun belgesel çekmeleri istenmiştir. Belgesel konuları çevre eğitimi dersi konularına uygun olarak konuların işlendiği hafta ders saatinde öğrencilere duyurulmuştur. Öğretmen adaylarına belgesellerini planlayıp çekmeleri için 3'er hafta zaman verilmiştir. Belgesel için metin yazma, gerekli bilgisayar programlarını kullanma ve belgeseli bir araya getirme eğitimlerini 2017-2018 eğitim öğretim yılı güz döneminde "Öğretim teknolojileri ve materyali geliştirme" dersi kapsamında öğrenen deney grubu öğretmen adayları bu araştırma kapsamında uygulama firsatı yakalamışlardır. Belgeseller ile ilgili sorunları rahatlıkla aşılması, öğretmen adaylarının belgesel ile ilgili sorularının hemen yanıtlanması ve belgesellerin toplanması amaciyla Edmodo sinıf yönetim aracı kullanılmıştır. Öğretmen adaylarına hazırlayacakları belgeselin adı, içeriği ve son yükleme tarihi ile ilgili bilgiler Edmodo programı üzerinden iletilmiştir. Belgesel çekerken yararlanabilecekleri dokümanlar yine Edmodo’ya yüklenmiştir. Öğretmen adaylarının belgesel çekerken karşılaştıkları güçlükler Edmodo programı üzerinden yazışarak giderilmiştir.

\section{Veri Toplama Aracı}

Araştırmada fen bilgisi öğretmen adaylarının ekosentrik. antroposentrik ve çevreye yönelik antipatik tutumlarını belirlemek amacıyla Thompson ve Barton (1994) tarafından geliştirilen “Ekosentrik. Antroposentrik ve Çevreye Yönelik Antipatik Tutum Ölçeği”” kullanılmıştır. Ölçeğin Türkçe'ye uyarlanması Erten (2007) tarafindan gerçekleştirilmiştir. Ölçek, “Ekosentrik Tutumları", "Antroposentrik Tutumları" ve "Çevrenin Korunmasına Yönelik Antipatik Tutumları" olmak üzere üç boyuttan oluşmaktadır. Ölçekte 7'li likert tipi derecelendirme kullanılmıştır. Erten (2007) ölçeğin güvenirlik çalışması sonucunda, Ekosentrik tutum alt boyutu için Cronbach $\alpha$ değerini .77, Antroposentrik tutum alt boyutu için Cronbach $\alpha$ değerini .78 ve üçüncü faktör olan çevrenin korunmasına yönelik antipatik tutum alt boyutu için Cronbach $\alpha$ değerini ise .92 olarak belirlemiştir. Bu çalışma kapsamında, Ekosentrik tutum alt boyutu için Cronbach $\alpha$ değeri .84, Antroposentrik tutum alt boyutu için Cronbach $\alpha$ değeri .85 ve Çevrenin korunmasına yönelik Antipatik tutum alt boyutu için Cronbach $\alpha$ değeri ise .89 olarak hesaplanmıştır. 


\section{Verilerin Analizi}

$\mathrm{Bu}$ araştırmada kullanılan verilerin varyanslarının homojenliği Levene testi ile, verilerin normalliği ise Shapiro-Wilk testi kullanılarak belirlenmiştir. Testlerin sonuçları doğrultusunda ön test karşılaştırmaları bağımsız t-testi kullanılarak yapılmıştır. Kontrol ve deney gruplarına ait grup içi karşılaştırmalar bağımlı t testi kullanılarak yapılmıştır. Kontrol ve deney grubunun son test karşılaştırmaları ise bağımsız t testi kullanılarak yapılmıştır.

Kontrol ve deney grubu öğrencilerinin deneysel çalışma öncesi ön test bağımsız t-testi sonucu, öğretmen adaylarının çevreye yönelik ekosenterik, antroposentrik ve antipatik tutumlarının arasında anlamlı bir fark olmadığına işaret etmektedir (Tablo 1).

Tablo 1. Kontrol ve deney grubunun ön test karş1laştırmaları

\begin{tabular}{llllllll}
\hline Ön tutum & Gruplar & $\mathrm{N}$ & $\overline{\mathrm{X}}$ & $\mathrm{SS}$ & $\mathrm{sd}$ & $\mathrm{t}$ & $\mathrm{p}$ \\
\hline Ekosentrik tutum & Kontrol grubu & 29 & 5.27 & .824 & 59 & -1.732 & .088 \\
& Deney grubu & 32 & 5.58 & .538 & & & \\
\hline Antroposentrik tutum & Kontrol grubu & 29 & 5.42 & .892 & 59 & .525 & .602 \\
& Deney grubu & 32 & 5.29 & .967 & & & \\
\hline Antipatik tutum & Kontrol grubu & 29 & 2.27 & 1.13 & 59 & 1.824 & .073 \\
& Deney grubu & 32 & 1.83 & .744 & & & \\
\hline
\end{tabular}

\section{Bulgular}

Bulgular bölümünde araştırmanın verilerinin istatistiksel sonuçları tablolar halinde sunulmuştur. Araştırmanın bulgularından kontrol grubu ön test son test karşılaştırmalarına (Tablo 2) bakıldığında öğretmen adaylarının ekosentrik tutum ortalamaları arasında anlamlı bir farklılık olmadığı görülmektedir ( $\left.\mathrm{t}_{56}=-1.086, \mathrm{p}>.05\right)$.

Tablo 2. Kontrol grubu öğretmen adaylarının ön test son test tutum karşılaştırmaları

\begin{tabular}{lllllllc}
\hline Kontrol grubu & Gruplar & $\mathrm{N}$ & $\overline{\mathrm{X}}$ & $\mathrm{SS}$ & $\mathrm{sd}$ & $\mathrm{t}$ & $\mathrm{p}$ \\
\hline Ekosentrik tutum & Ön test & 29 & 5.27 & .82498 & 56 & -1.086 & .282 \\
& Son test & 29 & 5.51 & .82439 & & & \\
\hline Antroposentrik tutum & Ön test & 29 & 5.42 & .89231 & 56 & .819 & .416 \\
& Son test & 29 & 5.21 & 1.06492 & & & \\
\hline Antipatik tutum & Ön test & 29 & 2.27 & 1.13962 & 56 & .45 & .655 \\
& Son test & 29 & 2.15 & .93672 & & & \\
\hline
\end{tabular}

Kontrol grubu öğretmen adaylarının antroposentrik tutum ortalamaları arasında da anlamlı bir farklılık olmadığı belirlenmiştir $\left(\mathrm{t}_{56}=.819, \mathrm{p}>.05\right)$. Benzer olarak kontrol grubu öğretmen 
adaylarının antipatik tutum ortalamaları arasında anlamlı bir farklılık olmadığı saptanmıştır $\left(\mathrm{t}_{56}=.45, \mathrm{p}>.05\right)$.

Tablo 3. Deney grubu öğretmen adaylarının ön test son test karşılaştırmaları

\begin{tabular}{llllllll}
\hline Deney grubu & Gruplar & $\mathrm{N}$ & $\overline{\mathrm{X}}$ & $\mathrm{SS}$ & $\mathrm{sd}$ & $\mathrm{t}$ & $\mathrm{p}$ \\
\hline Ekosentrik tutum & Ön test & 32 & 5.58 & .53854 & 62 & -2.545 & .01 \\
& Son test & 32 & 5.93 & .55956 & & & \\
\hline Antroposentrik tutum & Ön test & 32 & 5.29 & .96759 & 62 & -1.667 & .10 \\
& Son test & 32 & 5.66 & .80548 & & & \\
\hline Antipatik tutum & Ön test & 32 & 1.83 & .74491 & 62 & .53 & .59 \\
& Son test & 32 & 1.75 & .42626 & & & \\
\hline
\end{tabular}

Tablo 3'e bakıldığında deney grubu öğretmen adaylarının ekosentrik tutum ön test son test karşılaştırmaları arasında son test lehine anlamlı düzeyde farklılık olduğu görülmektedir $\left(\mathrm{t}_{62}=\right.$ 2.545, $\mathrm{p}<.05)$. Buna karşın deney grubu öğretmen adaylarının antroposentrik tutum $\left(\mathrm{t}_{62}=-1.667\right.$, $\mathrm{p}>.05)$ ve antipatik tutum $\left(\mathrm{t}_{62}=.53, \mathrm{p}>.05\right)$ ön test son test ortalamaları arasında anlamlı bir farkl1lık olmadı̆̆ 1 tespit edilmiştir.

Tablo 4. Kontrol ve deney grubu öğretmen adaylarının son test karşılaştırmaları

\begin{tabular}{lllllllc}
\hline Son tutum & Gruplar & $\mathrm{N}$ & $\overline{\mathrm{X}}$ & $\mathrm{SS}$ & $\mathrm{sd}$ & $\mathrm{t}$ & $\mathrm{p}$ \\
\hline Ekosentrik tutum & Kontrol grubu & 29 & 5.51 & .824 & 59 & -1.732 & $.022^{*}$ \\
& Deney grubu & 32 & 5.93 & .559 & & & \\
\hline Antroposentrik tutum & Kontrol grubu & 29 & 5.21 & 1.064 & 59 & .525 & .062 \\
& Deney grubu & 32 & 5.66 & .805 & & & \\
\hline Antipatik tutum & Kontrol grubu & 29 & 2.15 & .936 & 59 & 1.824 & $.032^{*}$ \\
& Deney grubu & 32 & 1.75 & .426 & & & \\
\hline
\end{tabular}

Tablo 4'e göre, kontrol ve deney grubu öğretmen adaylarının ekosentrik tutum son test karşılaştırmaları arasında deney grubu lehine anlamlı bir farklılık olduğu görülmektedir $\quad\left(\mathrm{t}_{59}=-\right.$ $1.732, \mathrm{p}<.05)$. Yine deney grubu öğretmen adaylarının antipatik tutum ortalamaları arasında deney grubu lehine anlamlı bir farklılık olduğu belirlenmiştir $\left(\mathrm{t}_{59}=1.824, \mathrm{p}<.05\right)$. Fakat kontrol ve deney grubu öğretmen adaylarının antroposentrik tutumları arasında anlamlı bir farklılık elde edilememiştir $\left(\mathrm{t}_{59}=.525, \mathrm{p}>.05\right)$.

\section{Tartışma}


Şehir yaşantısının bireyleri doğadan soyutladığı dikkate alınacak olursa sadece çevresel bilginin çevre eğitimi için yeterli olmayacağı bilinmektedir. Bu nedenle bireylerin doğa ile birebir etkileşim olanağı bulacakları öğretim etkinliklerinin gerekliliği vurgulanmaktadır (Özdemir, 2010). Bu noktada fen bilimleri öğretmen adaylarına doğa ile yakın temas edebilecekleri temalar ile belgesel çekmelerinin desteklenmesi izlenebilecek yollardan biri olarak karşımıza çıkmaktadır. Sauve (2005) çağdaş çevre eğitimi yaklaşımını çevreyi sürdürülebilir eylemlere yönelik, sosyokültürel temelli bütüncül bir yaklaşımla ele almaktadır. Çevre eğitimi kapsamında sayılan, fen bilimleri öğretim programındaki (2018) 5. Sınıf "İnsan ve Çevre” ve 8. sınıf "Enerji dönüşümleri ve Çevre Bilimi” ünitelerinin verimli, bireysel özelliklere hitap eden, araştırmaya dayalı, eyleme dönüştüren ve çok boyutlu tartışılmasını sağlayan çağdaş öğretime dönüştürülmesi ancak bu özelliklere sahip öğretmenler tarafından gerçekleştirilebilir. Duyuşsal kazanımların gerçekleştirilmesi için, çevreye yönelik yüksek düzeyde olumlu tutumlara sahip ve tutum geliştirmeye yönelik yöntemleri etkili uygulayabilen fen bilimleri öğretmenlerine ihtiyaç duyulmaktadır (Kim ve Fortner, 2006). Böylece, çevreyi korumaya yönelik duygu, düşünce ve davranışların geliştirilmesi ile çevreye dost bireylerin yetiştirilmesi mümkün olacaktır. Bu nedenle bu araştırmada; çevre eğitimi dersi kapsamında, belgesel çekme etkinlikleri yoluyla, lisans düzeyinde, öğretmen adaylarının doğayı yakından tanımaları, incelemeleri, anlamaları ve analiz etmeleri sağlanmaya çalışılmıştır. Yapılan çalışmalar, çevre derslerinde kullanılan geleneksel öğretim yönteminin öğrencileri, çevre ilgili teorik bilgileri ezberlemeye yönelterek, duyuşsal ve psikomotor yeterliliklerin kazandırılmasında yetersiz kaldığı belirtilmektedir (Karlegger, 2010; Marinopoulos ve Stavridou, 2002; Oluk ve Özalp, 2007). Bu nedenle öğrencilerin öğrenme etkinliklerin bir parçası olduğu aktif öğrenme etkinlikleri ile desteklenen çevre eğitiminin öğrencilerin çevresel bilgi, tutum ve davranışlarına etkisini inceleyen çalışmalar gün geçtikçe önem kazanmaktadır. Bu bağlamda konuyla ilgili yapılan çalışmalar incelendiğinde, öğrencilerin aktif oldukları etkinliklerle desteklenen çevre derslerinin öğrencilerin çevresel tutumları, çevresel faaliyetlere katılımları ve çevre duyarlılıklarını (Alvarez, Fuente, Peralas ve Garcia, 2002; Bauer, 2006; Oluk ve Özalp, 2007; Stern, Powell ve Ardoin, 2008) arttırdığı görülmektedir. Özellikle sınıf dışı etkinliklerle desteklenen çevre eğitiminin çevreye yönelik tutumları olumlu yönde geliştirdiği vurgulanmaktadır (Wolf-Watz, Sandell ve Fredman, 2011). Nitekim bu araştırma kapsamında, öğretmen adaylarının çevresel belgeseller hazırlayarak öğrenme sürecinin bir parçası 
olmaları sağlanmaya çalışılmıştır. Çevre temalarına uygun belgesel çekme etkinlikleri sırasında öğretmen adayları doğa ile baş başa kalmışlardır. Öğretmen adayları, doğa belgeseli çekme eylemi ile öğretim programı ile yaşam arasındaki bağlantıyı kurma firsatı yakalamışlardır. Belgeselleri sınıf ortamında izleyip tartışarak dünü, bugünü ve geleceği analiz etmeye çalışmışlardır. Tüm bu etkinlikler süresince öğretmen adayları farklı perspektiflerden doğayı inceleme firsatı yakalamışlardır. Doğal yaşamın insan faaliyetleri tarafından nasıl etkilendiğini birebir görme şansı bulmuşlardır. İnsanın doğanın bir parçası olduğu gerçekliğini bir kez daha irdelemişlerdir. Doğal yaşamsal dengenin bileşenleri arasındaki ilişkileri ve bu ilişkilerin bozulması sonucunda gerçekleşen ve gerçekleşebilecek olayları gözlemleme firsatı yakalamışlardır. Bir dönem boyunca gerçekleştirilen etkinlikler ile deney grubu öğrencilerinin insanı merkeze alan değil doğayı merkeze alan çevre yaklaşımını benimsemeleri sonucu ortaya çıkmıştır. Doğayı merkeze alan ekosentrik tutumların geliştirilmesi literatürde olumlu olarak kabul edilmektedir. Bu bağlamda bu çalışma ile öğretmen adaylarının çevreye yönelik ekosentirik tutumları geliştirilmiştir. Bir dönem boyunca gerçekleştirilen etkinliklerle deney grubu öğretmen adaylarının literatürde olumsuz olarak kabul edilen antipatik tutumlarının azaldığı belirlenmiştir. Bu durum doğa belgeseli çekme etkinliklerinin çevreye yönelik var olan negatif tutumların düşürülebileceği sonucunu ortaya çıkarmaktadır.

\section{Sonuç ve Öneriler}

Araştırmada, fen bilimleri dersi öğretmen adaylarının gerçekleştirdikleri belgesel çekme etkinliklerinin çevreye ekosentrik yaklaşımlarını geliştirmekte etkili olduğu sonucuna ulaşılmıştır. Belgesel çekme etkinliklerinin öğretmen adaylarının antipatik tutum düzeyini de düşürdüğü belirlenmiştir. Bu sonuçlar ışığında, lisans düzeyinde çevre eğitimi derslerinin sınıf dışı ortamlara taşınması önerilmektedir.

\section{Makalenin Bilimdeki Konumu}

Matematik ve Fen Bilimleri Eğitimi/Çevre Eğitimi

\section{Makalenin Bilimdeki Özgünlüğ̈̈}


Literatür incelendiğinde, farklı öğretim kademesindeki öğrencilerin (Atlı vd., 2015; Kopnina ve Cocis, 2017a), üniversite öğrencilerinin (Casey ve Scott, 2006; Kortenkamp ve Moore, 2001; Crumpei ve ark., 2014; Kopnina, 2013; Kopnina ve Cocis, 2017b), öğretmen adaylarının (Erten ve Aydoğdu, 2011; Karakaya ve Çobanoğlu, 2012; Sürmeli ve Saka, 2013; Alpak ve ark., 2017) ve farklı meslek gruplarına dahil bireylerin (Akgül ve ark., 2007; Baltacı ve ark., 2015) örneklem olarak seçildiği araştırmalar dikkatleri çekmektedir. Bu araştırmaların tamamının çevresel tutum yaklaşımlarının genel durumunu ortaya koymak için tarama yöntemiyle gerçekleştiği görülmektedir. Öğretmen adaylarının çevresel tutum yaklaşımlarını değiştirmeye yönelik deneysel çalışmaya rastlanmamıştır. Bu yönüyle araştırmanın özgün boyutu ortaya çıkmaktadır. 


\section{Kaynakça}

Allport, G. W. (1935). Attitudes. In C. Murchison (Ed.), Handbook of Social Psychology. (pp.798884). Worcester, MA: Clark University Press.

Alpak-Tunç, G. ve Yenice, N. (2017). An analysis of preservice teachers' moral considerations about environment and their attitudes towards sustainable environment. International Electronic Journal of Environmental Education, 7(1), 17-33.

Álvarez, P., Fuente, E.I, Perales, F.J. ve Garcia, J. (2002). Analysis of a quasi-experimental design based on environmental problem solving for the 1nitial training of future teachers of environmental education. Journal of Environmental Education, 33(2), 19-21.

Akgül, M. B., Birinci, C., Göral, Ş., ve Karaküçük, S. (2017). An investigation of ecocentric and anthropocentric attitudes and antipathy towards environment in athletes. Journal of Human Sciences, 14(4), 3405-3414. doi:10.14687/jhs.v14i4.4680

Anderson, M. W., Teisl, M. F., Criner, G. K., Tisher, S., Stewart, S. Hunter, M. L., ve Norton, S. A. (2007). Attitude change of undergraduate students in general education courses. Journal of General Education, 56(2), 149-168. https://doi.org/10.1353/jge.2007.0016

Anand, S.V. (2013). Global environmental issues. Open Access Scientific Reports, v.2,i.2, 2-9 doi:10.4172.

Atlı, K., Uzun, N., Saraç, C., Sağlam, N. ve Sağlam, S. (2015). Öğrencilerin ekosentrik, antroposentrik ve çevreye yönelik antipatik tutumlarının akademik başarıları ile ilişkisi. International Journal of Innovative Research in Education, 2(1), 39-47.

Bahk, C. M. (2010). Environmental education through narrative films: 1mpact of medicine man on attitudes toward forest preservation. The Journal of Environmental Education, 42(1), 1-13. https://doi.org/10.1080/00958960903479811

Baltacı, F., Yirik, Ş., Sargın, S.A. ve Yumuşak, A. (2015). From the ecocentric and anthropocentric perspectives, a survey of future tourism entrepreneurs' attitudes toward environmental 1ssues: Sample of Akdeniz University, International Journal of Humanities and Social Science Vol. 5, No. 1,139-143

Bauer, J. (2006). Perspective coverage with future generations as a means to increase environmental protection behavior-an experiment. (Unpublished doctoral dissertation). Friedrich-Alexander-Universitaet, Nuernberg, 
Birleşmiş Milletler, (2002 ). Report of The World Summit on Sustainable Development. New York Germany. http://kmgne.de/wp-content/uploads/2013/05/judithbauer2006.pdf

Casey, P.J. ve Scotth, K. (2006). Environmental concern and behaviour in an Australian sample within an ecocentric - anthropocentric framework. Australian Journal of Psychology, Vol. 58, No. 2, pp. $57-67$.

Crumpei, İ., Boncu, S. ve Crumpei, G. (2014). Environmental attitudes and ecological moral reasoning in romanian students. Procedia - Social and Behavioral Sciences, 114, 461 - 465

Dunlap, R. E. ve Van Liere, K. D. (1978). The new environmental paradigm. Journal of Environmental Education, 9,10-19.

Ergülen, A. ve Büyükkeklik, A. (2008), Sürdürülebilir kalkınmanın ekonomik ve çevre boyutları açısından atık yönetimi ve e-atıklar, Niğde Üniversitesi Iktisadi ve İdari Bilimler Fakültesi Dergisi, Cilt:1, Say1:2, ss:19-30

Erten, S. (2007). Ekosentrik, antroposentrik ve çevreye yönelik antipatik tutum ölçeğinin Türkçe’ye uyarlama çalışması. Eurasian Journal of Education Research, 28, 67-74.

Erten, S. ve Aydoğdu, C. (2011). Türkiyeli ve Azerbaycanlı öğrencilerde ekosentrik, antroposentrik ve çevreye karşı antipatik tutum anlayışları. Hacettepe Üniversitesi Eğitim Fakültesi Dergisi, 41, 158-169.

Ewert, A., Place, G. ve Sibthorp, J. (2005). Early-life outdoor experiences and an individual's environmental attitudes. Leisure Sciences, 27(3), 225-239, doi: 10.1080/01490400590930853.

Greenwald, A. G. (1989). Why are attitudes important? In A. R. Pratkanis, S. J. Breckler ve A. G. Greenwald (Eds.), Attitude Structure and Function (pp. 1-10). Hillsdale, NJ, England: Lawrence Erlbaum Associates, Inc.

Godmilow, J. ve Shapiro, A.L. (1997). How real is the reality in documentary film? History and Theory, 36(4), 80-101. https://doi.org/10.1111/0018-2656.00032

Gürlük, S. (2001), Dünyada ve Türkiye'de kırsal kalkınma politikaları ve sürdürülebilir kalkınma, Uludă̆ Üniversitesi İktisat Fakültesi Dergisi, Cilt:19, Sayı:4.

Judi, H.M., Sahari, N., Ashaari, H.M. ve Wook, M.T. (2010). Students profile based on attitude towards statistics, Procedia Social and Behavioral Sciences, 18, 266-272. 
Karakaya, Ç. ve Çobanoğlu E. O. (2012). İnsanı merkeze alan (antroposentrik) ve almayan (nonantroposentrik) yaklaşımlara göre eğitim fakültesi son sınıf öğrencilerinin çevreye yönelik bakış açıları, Türk Fen Eğitimi Dergisi, 9(3), 23 - 35.

Karlegger, A. (2010). Nature connectedness and environmental identity in adolescence - The impact of nature contact and social context. (Unpublished master"s thesis). University of Vienna, Vienna, Austria. http://othes.univie.ac.at/9030/1/2010-02-26 0208590.pdf.

Karpiak, C. P. ve Baril, G. L. (2008). Moral reasoning and concern for the environment. Journal of Environmental Psychology,28, 203-208. http://dx.doi.org/10.1016/j.jenvp.2007.12.001

Kim, C. ve Fortner, R. W. (2006). Issue-specific barriers to addressing environmental sssues in the classroom: an exploratory study. The Journal of Environmental Education, 37: 15-22.

Khan, S.H. (2013). A study of attitude towards environmental awareness in relation to certain variables among senior secondary school students. Scholarly Research Journal for Interdisciplinary studies, v.1,1258-1264.

Kopnina, H. (2013). Evaluating education for sustainable development (ESD): Using ecocentric and anthropocentric attitudes toward the sustainable development (EAATSD) scale, Environment, Development and Sustainability, 15,607-623.DOI 10.1007/s10668-012-9395$\mathrm{Z}$

Kopnina, H. ve Cocis, A. (2017a). Environmental education: Reflecting on application of environmental attitudes measuring scale in higher education students, Education Sciences, 7, 69; doi:10.3390/educsci7030069

Kopnina, H. ve Cocis, A. (2017b). Testing ecocentric and anthropocentric attitudes toward the sustainable development (EAATSD) Scale with Bachelor Students. European Journal of Sociology and Anthropology, 2(1), 2. doi: 10.20897/ejsa.201702

Kortencamp, K.V. ve Moore, C.F. (2001). Ecocentrism and anthropocentrism: moral reasoning about ecological commons dilemmas, Journal of Environmental Psychology, 21, 261-272

Louv, R. (2008). Last Child in The Woods: Saving our Children from Nature-Deficit Disorder. Chapel Hill, Nc:Algonquin.

MacKinnon, B. ve Fiala, A. (2014). Ethics: Theory and Contemporary Issues. Nelson Education. 
Marinopoulos, D. ve Stavridou, H. (2002) The influence of a collaborative learning environment on primary students' conceptions about acid rain, Journal of Biological Education, 37:1, 1825, DOI: $10.1080 / 00219266.2002 .9655841$

MEB (2018). Fen Bilimleri Öğretim Programı. Ankara

Nordlund, A. M. ve Garvill, J. (2002). Value structures behind proenvironmental behaviour. Environment and Behavior, 34,740-756. http://dx.doi.org/10.1177/001391602237244

Oelschlaeger, M. (1992). Introduction. In M. Oelschlaefer (Ed.), The wilderness condition: Essays on environment and civilization (pp. 1-20). San Francisco, CA: Sierra Club Books.

Oluk, S. ve Özalp, I. (2007). The teaching of global environmental problems according to the constructivist approach: as a focal point of the problem and the availability of concept cartoons. Educational Sciences: Theory ve Practice, 7 (2), 881-896

Özdemir, O. (2010). Doğa deneyimine dayalı çevre eğitiminin ilköğretim öğrencilerinin çevrelerine yönelik algı ve davranışlarına etkisi. Pamukkale Üniversitesi Eğitim Fakültesi Dergisi, 27, 125- 138.

Palmer, M. ve Lee, P. (2009). StoriesWorth telling: A guide to creating student-led documentaries, Apple Inc. Erişim tarihi: 12.01.2019. Erişim adresi; http://images.apple.com/education/docs/Documentary_Guide_10-09.pdf

Paschalidis, G. (2006). The language of documentary. Unpublished manuscript. Department of Journalism and Mass Communication, Aristotle University of Thessaloniki.

Poortinga, W., Steg, L. ve Vlek, C. (2004). Values, environmental concern and environmental behavior a study into household energy use. Environment and Behavior, Vol. 36 No. 1, 7093. Do1: $10.1177 / 0013916503251466$

Repetto, R. (1992). Accounting for environmental assets. Scientific American, 266(6), 94-100.

Rowe, D. (2002). Environmental Literacy and Sustainability as Core Requirements: Success Stories and Models. in W.L. Filho, (Ed.), Teaching Sustainability at Universities (pp. 79103). Frankfurt: Peter Lang.

Selvi, M. (2007). Biyoloji Öğretmeni Adaylarının Çevre Kavramları ile İlgili Algılamalarının Değerlendirilmesi. Yayınlanmamış doktora tezi, Gazi Üniversitesi, Eğitim Bilimleri Enstitüsü, Ankara. 
Schultz, P.W. (2000). Empathizing with nature: The Effects of perspective taking on concern for environmental issues. Journal of Social Issues, 56(3), 391-406.

Sauve, L. (2005). Currents in environmental education: Mapping a complex and evolving pedagogical field. Canadian Journal of Environmental Education, 10(1), 11-37.

Sürmeli, H. ve Saka M. (2013). Preservice teachers' anthropocentric, biosentric and ecocentric environmental ethics approaches. Internaional Journal of Academie Research, 5(5), 159 163.

Stern, M. J., Powell, R. B., ve Ardoin, N. M. (2008). What difference does it make? Assessing outcomes from participation in a Residential Environmental Education program. The Journal of Environmental Education, 39(4), 31.

Taff, A., Aziz, A., Haron, S.R., Rashid, N.M. ve Yasim, M.M. (2010). Residential outdoor education and environmental attitudes: An examination in a Malaysian University, Journal of Outdoor Recreation, Education, and Leadership, Vol. 2, No. 3, pp. 198-216

Tietenberg, T. (2006). Environmental and Natural Resource Economics. New York: HarperCollins Publishers.

Thompson, S. C. G. ve Barton, M.A. (1994). Ecocentric and anthrocentric attitudes toward the environment. Journal of Environmental Psychology. 14: 149-157.

Wolf-Watz, D., Sandell, K., ve Fredman, P. (2011). Environmentalism and tourism preferences: a study of outdoor recreationists in Sweden. Scandinavian Journal of Hospitality and Tourism, 11(2), 190-204. https://doi.org/10.1080/15022250.2011.583066 


\section{EXTENDED ABSTRACT}

\section{Introduction}

The importance of sustainable development has increased due to growing environmental problems affecting people's living conditions negatively and the projected economic developments decrease stemmed from the insufficiency of natural resources. Sustainable development, defined as the development strategy for long-term prosperity and the use of natural resources to meet the needs of future generations, is one of the issues discussed in the world agenda. Sustainable development is generally considered in three dimensions: social, environmental and economic. Recently, ecocentric and anthropocentric approaches related to the environmental dimension of sustainable development are in the foreground. In both approaches, although the theory of sustainable development is important in protecting the living organisms in their natural environment, the theory they rely on is different from each other. The environmental documentary has the ability to make the reality of environmental problems dramatic and make the audience an active part of the change necessary to address environmental crises. If environmental documentaries are combined with the technological opportunities offered by contemporary audiovisual instruments, it becomes a valuable educational material. With its rich content, environmental documentaries offer multiple uses as teaching materials at all levels of education. They can be easily adapted to specific teaching needs and can serve as a tool for the development of environmental awareness of students. One of the reasons why the attitudes are practical and theoretically important is that they have predictable and very strong effects on behaviour.

\section{Purpose of the Study}

In this study, the effect of making documentaries on science student teachers' attitudes towards the environment for sustainable development was investigated.

\section{Method}

In this study, pre-test and post-test control group experimental design was used. Science student teachers in the control group were taught through the methods the instructor has been using in the course in general including PowerPoint presentations, outdoor activities, visiting a recycling plant in the town. Participants in the experimental group made documentaries based on the selected themes related to the topics studied within the course. Ecocentric, Anthropocentric and 
Environmental Antipathic Attitude Scale developed by Thompson and Barton (1994) were used in order to determine science student teachers' ecocentric, anthropocentric and antipathic attitudes towards the environment.

\section{Results and Discussion}

The results of the pre-test independent t-test of control and experimental group students indicate that there was not any statistically significant difference between pre-service science teachers' pre-test ecocenteric, anthropocentric and antipathic attitudes prior to the experimental process. When the results of the pre-test and post-test comparisons of the control group were examined, it appears that there was not any statistically significant difference between the pre-test and post-test scores. The study revealed a statistically significant difference between the pre-test post-test comparisons of the experimental group science student teachers' ecocentric attitudes in favour of the final test. While the examination of the findings did not show any statistically significant between the experimental student teachers' anthropocentric and antipathic attitudes toward the environment. The study displayed a statistically significant difference in science student teachers' ecocentric and antipathic attitudes toward the environment in favour of the experimental group. While the study did not find any statistically significant difference between the two groups anthropocentric attitudes. Previous studies carried out in the field indicate that traditional teaching method used in environmental courses is inadequate in gaining affective and psychomotor qualifications by directing students to memorize theoretical knowledge related to the environment. The findings of the study are supportive of the previous studies in that environmental education supported by extracurricular activities positively improved attitudes towards the environment. 